\title{
Early Warning of Foundation Settlement Deformation for Ballastless High-Speed Railway Tracks
}

\author{
Dongwei Li ${ }^{1}$, Yuankun Xu${ }^{1}$, Ranli Chen ${ }^{2}$ \\ ${ }^{1}$ School of Environment Science and Spatial Informatics, China University of Mining and Technology, Xuzhou, \\ China \\ ${ }^{2}$ Surveying and Mapping Engineering, Shijiazhuang Institute of Railway Technology, Shijiazhuang, China \\ Email:104104lidongwei@163.com, xuyuankun5200@163.com,272172064@qq.com
}

Received 8 September 2015; accepted 16 October 2015; published 23 October 2015

\section{Abstract}

There has been rapid development of high-speed railway lines, especially passenger-dedicated railway lines, in China. Trains are traveling at speeds exceeding $250 \mathrm{~km}$ per hour and they require highly smooth tracks to ensure safety. However, there have been no in-depth studies on the early warning of the settlement of high-speed railway lines in China or abroad. Most methods use a simple model based on data processing and decision rules. The core issues of early warning lie in the science and rationality of decision rules. The present paper therefore investigates novel and critical indexes for the warning of settlement under high-speed railway lines according to existing norms and field data, and several essential indexes of deformation warning are suggested through theoretical and experimental analysis.

\section{Keywords}

High-Speed Railway, Settlement, Prediction Model, Early Warning

\section{Introduction}

There have been few studies on early-warning methods for high-speed railway settlement and displacement. Most methods rely on a simple model derived by processing data and setting decision rules. According to theory suggested by the research scholar Chen Shanxiong, general judgement rules involve a core index, controlling index and general index [1]. These three indexes have different importance in practical applications but a decision model adopted by a warning system must take all three into consideration.

\section{General Warning Mechanics}

According to the norms of high-speed railway surveying [2], relevant rules applied to the Wuhan-Guangzhou and recently constructed Hefei-Fujian passenger-dedicated lines, and the actual requirements of projects that assess settlement and displacement under high-speed railway tracks, we conclude the importance of several ex- 
isted indexes that can be used in the warning of structural subsidence and deformation under railway lines. These indexes and their associated criteria are described as follows.

(1) In the assessment of roadbeds and bridges, if the observation period is more than three months after the completion of the major structure, the subsidence should fluctuate no more than $3.0 \mathrm{~mm}$ and the maximum increment of subsidence should be no greater than $\pm 2 \mathrm{~mm}$. Meanwhile, there should be no continuous subsidence in the last four groups of observation data (with an observation period exceeding 1 month) for constructions to be considered of meeting the requirements.

(2) Using actual load and field data for regression analysis and prediction and then determining the trend of deformation, the correlation coefficient of the regression curve should be no less than 0.92.

(3) For those surveying points that have not passed the foregoing assessment criteria, if the overall trend of a settlement curve is convergent in the three months following the completion of a major structure, the survey point is thought to pass the assessment. The survey point can be considered an exceptional point in the curve fitting process but it must remain under observation.

(4) The ratio of a surveying point's present subsidence value to its maximum prediction value must exceed $75 \%$.

(5) The post-construction difference between adjacent abutments in statically determinate structures should be no greater than $5 \mathrm{~mm}$ relative to the ballastless bridge floor and deck.

(6) The difference between the final forecasted settlement and the designed settlement for the same monitoring section should not exceed $10 \mathrm{~mm}$.

(7) The subsidence of each monitoring section should be no greater than $15 \mathrm{~mm}$.

As seen from the above-mentioned indexes and criteria, we can start from a single point and non-uniform settlement in exploring a method of warning about subsidence and deformation under high-speed railway lines.

\section{Settlement Warning of Single Point}

A warning of single-point subsidence mainly refers to surveying points of any observation section after construction. The survey includes two periods, the period in which ballastless tracks are laid and the period of operation. A feasible way of monitoring and warning subsidence during the latest warning process is to take existing settlement into account and then calculate the results in a year, since the ordinary operating cycle of a highspeed railway is 100 years and cannot be used directly.

There are two forms of subsidence for each single point, one being sudden subsidence, which may cause large and destructive deformation in a short time, and the other being slow subsidence, which may exceed the limits of relevant norms over time.

Sudden subsidence is universally seen in construction projects. Poor geological structures such as red soils and karst caves, as well as outburst floods and continuous heavy rainfalls, usually result in the large settlement of railway tracks; hence, we must issue a warning in such cases. For unapparent factors that may lead to sudden subsidence, a warning is made as a result of persistent monitoring following construction.

Table 1 gives the frequency of observing foundation settlement. The table implies that seven normal postconstruction observations should be carried out in the first year. The restriction of post-construction settlement in engineering surveying norms for a high-speed railway is $15 \mathrm{~mm}$, and the absolute value between two observations in a year cannot exceed $2 \mathrm{~mm}$.

Slow post-construction settlement has a much weaker effect on the running of a high-speed railway compared with sudden single-point subsidence. However, it may also cause severe damage when it reaches a certain extent owing to a lack of monitoring. We must therefore pay close attention to its developing trend. Table 2 presents 15 groups of settlement data where stable conditions have been reached under a constant load. The table gives the daily, weekly, monthly and annual values of subsidence.

The table shows that the annual settlements for sections 1, 6, 8, 9 and 13 exceed $15 \mathrm{~mm}$. The trends of subsidence in these sections are illustrated in Figures 1-5. The red line denotes the linear trend in each case.

We next select the data for section 2, which is continuously within subsidence limits and whose developing trend is shown in Figure 6. An obvious linear tendency can be seen in Figures 1-5 illustrating developing trend of data groups exceeding limits. The subsidence limit of $15 \mathrm{~mm}$ can be quantized as the indexes given in Table 3. We see that a warning should be issued for subsidence of $0.3 \mathrm{~mm}$ weekly and $1.2 \mathrm{~mm}$ monthly. 


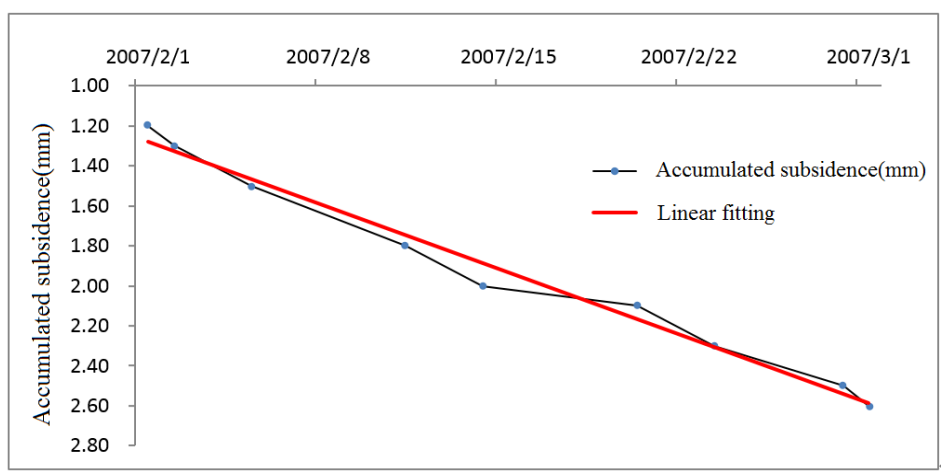

Figure 1. Post-construction foundation settlement developing trend of No.1.

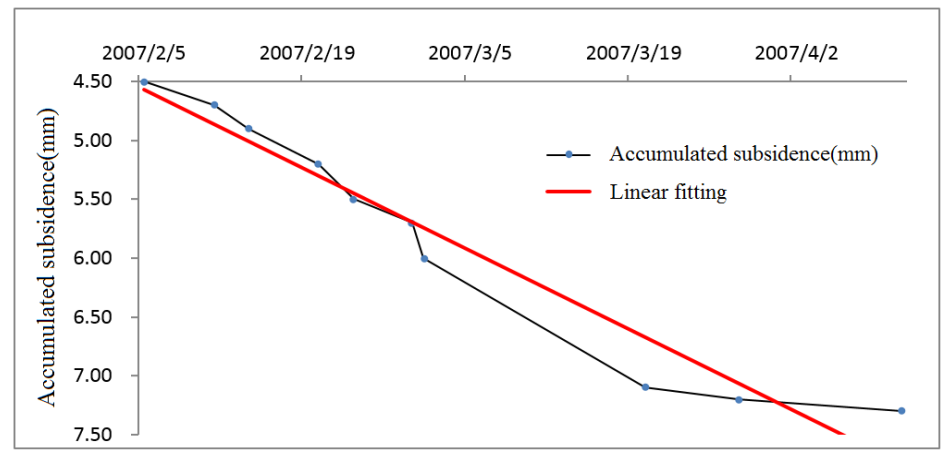

Figure 2. Post-construction foundation settlement developing trend of No.6.

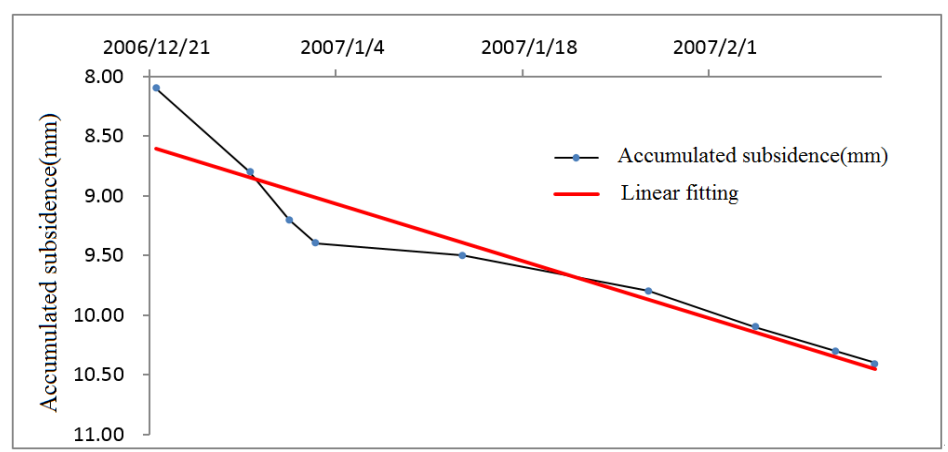

Figure 3. Post-construction foundation settlement developing trend of No.8.

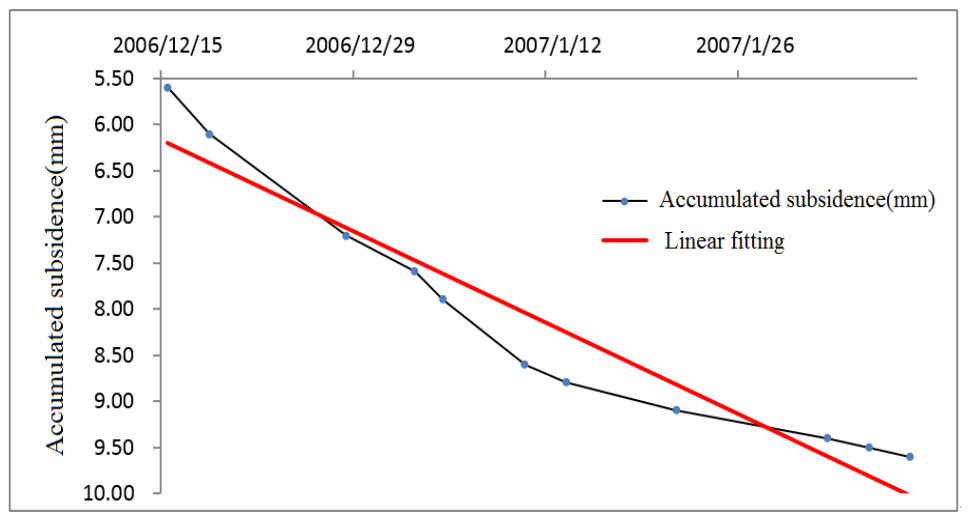

Figure 4. Post-construction foundation settlement developing trend of No.9. 


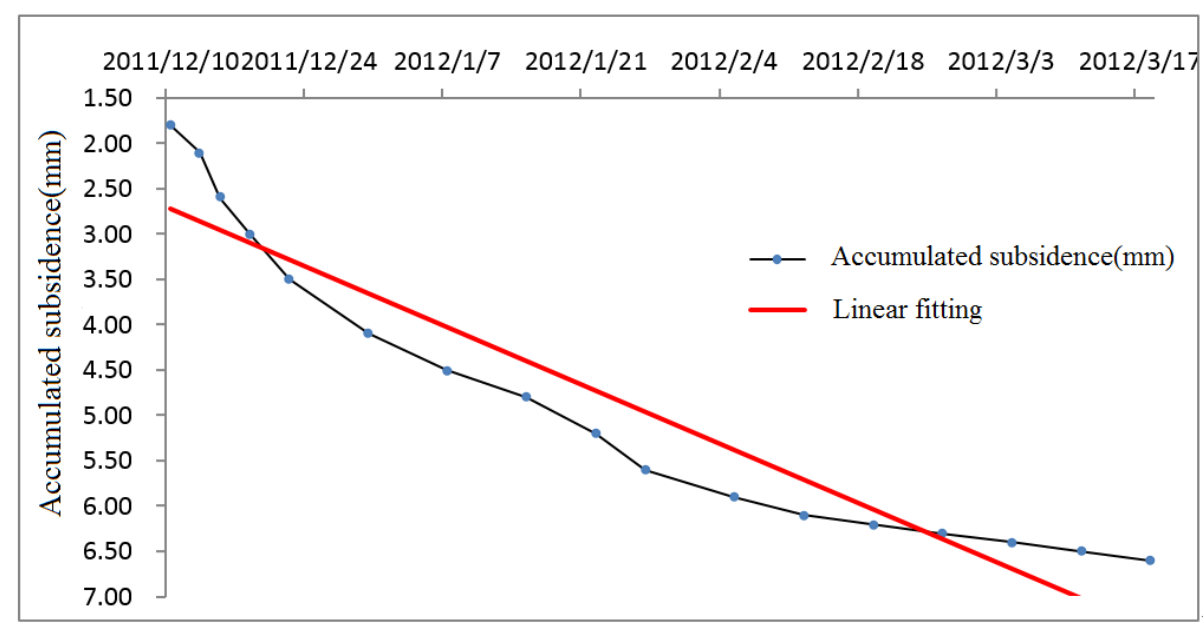

Figure 5. Post-construction foundation settlement developing trend of No.13.

Table 1. Frequency of post-construction foundation settlement observation in one year.

\begin{tabular}{|c|c|c|}
\hline Observation stage & \multicolumn{2}{|c|}{ Observation frequency } \\
\hline & The first month & biweekly \\
\hline \multirow{2}{*}{$\begin{array}{c}\text { After laying } \\
\text { ballastless tracks }\end{array}$} & The second and third months & monthly \\
\hline & The third to twelfth months & trimonthly \\
\hline
\end{tabular}

Table 2. Subsidence value from constant load period to stable conditions in different time scales.

\begin{tabular}{|c|c|c|c|c|c|c|}
\hline $\begin{array}{l}\text { Section } \\
\text { number }\end{array}$ & $\begin{array}{c}\text { Accumulated } \\
\text { Time(d) }\end{array}$ & $\begin{array}{l}\text { Accumulated } \\
\text { subsidence } \\
(\mathrm{mm})\end{array}$ & $\begin{array}{l}\text { Average daily } \\
\text { subsidence } \\
(\mathrm{mm})\end{array}$ & $\begin{array}{l}\text { Average weekly } \\
\text { subsidence } \\
(\mathrm{mm})\end{array}$ & $\begin{array}{l}\text { Average monthly } \\
\text { subsidence } \\
\text { (mm) }\end{array}$ & $\begin{array}{l}\text { Average annually } \\
\text { subsidence } \\
\text { (mm) }\end{array}$ \\
\hline No.1 & 29 & 1.50 & 0.05 & 0.36 & 1.55 & 18.88 \\
\hline No.2 & 173 & 2.60 & 0.02 & 0.11 & 0.45 & 5.49 \\
\hline No.3 & 146 & 2.10 & 0.01 & 0.10 & 0.43 & 5.25 \\
\hline No.4 & 136 & 2.70 & 0.02 & 0.14 & 0.60 & 7.25 \\
\hline No.5 & 146 & 2.30 & 0.02 & 0.11 & 0.47 & 5.75 \\
\hline No.6 & 68 & 4.10 & 0.06 & 0.42 & 1.81 & 22.01 \\
\hline No.7 & 29 & 1.10 & 0.04 & 0.27 & 1.14 & 13.84 \\
\hline No.8 & 57 & 2.80 & 0.05 & 0.34 & 1.47 & 17.93 \\
\hline No.9 & 57 & 4.50 & 0.08 & 0.55 & 2.37 & 28.82 \\
\hline No.10 & 87 & 2.20 & 0.03 & 0.18 & 0.76 & 9.23 \\
\hline No.11 & 75 & 1.80 & 0.02 & 0.17 & 0.72 & 8.76 \\
\hline No.12 & 65 & 1.60 & 0.02 & 0.17 & 0.74 & 8.98 \\
\hline No.13 & 102 & 5.10 & 0.05 & 0.35 & 1.50 & 18.25 \\
\hline No.14 & 122 & 4.30 & 0.04 & 0.25 & 1.06 & 12.86 \\
\hline No.15 & 110 & 3.70 & 0.03 & 0.24 & 1.01 & 12.28 \\
\hline
\end{tabular}




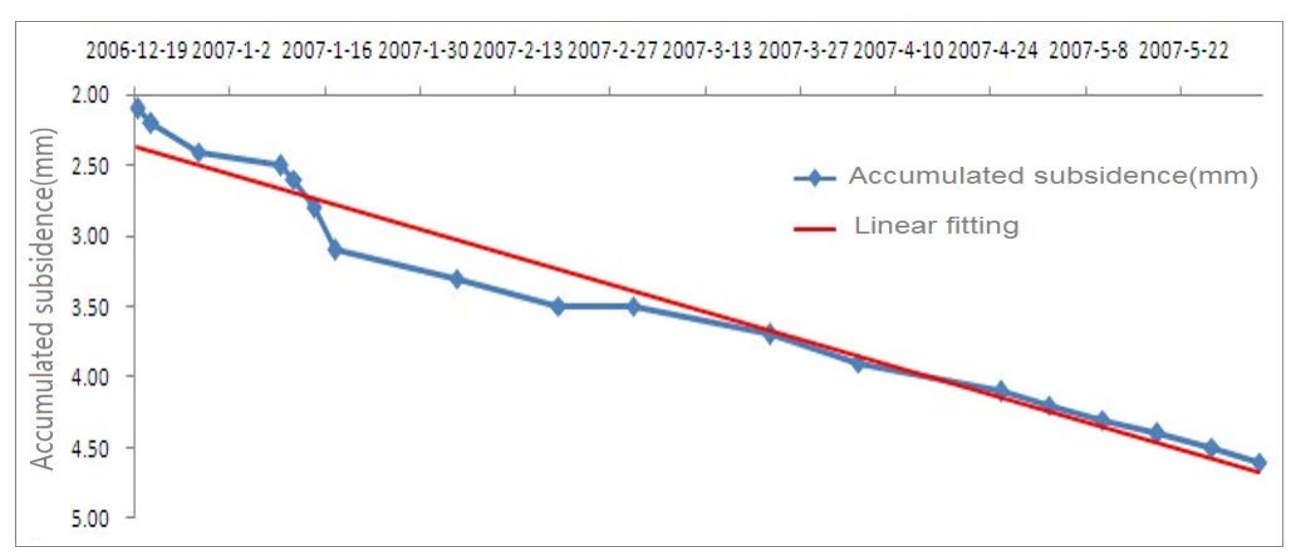

Figure 6. Post-construction foundation settlement developing trend of No.2.

Table 3. Post-construction quantized indexes in a year.

\begin{tabular}{cccccc}
\hline $\begin{array}{c}\text { Section } \\
\text { number }\end{array}$ & $\begin{array}{c}\text { Accumulated } \\
\text { Time(d) }\end{array}$ & $\begin{array}{c}\text { Average annually } \\
\text { subsidence }(\mathrm{mm})\end{array}$ & $\begin{array}{c}\text { Average daily } \\
\text { subsidence(mm) }\end{array}$ & $\begin{array}{c}\text { Average weekly } \\
\text { subsidence(mm) }\end{array}$ & $\begin{array}{c}\text { Average monthly } \\
\text { subsidence(mm) }\end{array}$ \\
\hline Standard section & 365 & 15 & 0.04 & 0.29 & 1.2 \\
\hline
\end{tabular}

\section{Warning of Un-Uniformed Subsidence}

Non-uniform settlement after construction undermines the riding comfort and smoothness of rails, may prevent trains from travelling quickly, and may even cause serious accidents. However, there have been few studies on the determination of non-uniform subsidence indexes and criteria and the early warning of non-uniform subsidence.

According to railway design guidelines [3] and temporary provisions of railway design [4], and taking the control method for uneven foundation settlement in Germany as an example, the existed corresponding requirement in China is that the minimum radius of the vertical curve should accord with equation 1 after adjusting for the elevation of the rail surface.

$$
R_{a}=0.4 V_{E}^{2}
$$

Here $R_{a}(\mathrm{~m})$ denotes the radius of the vertical curve and $V_{E}(\mathrm{~km} / \mathrm{h})$ denotes the designed speed.

We thus get the first warning index for non-uniform subsidence. In the example of a passenger-dedicated line with a train reaching a speed of $300 \mathrm{~km}$ per hour, the radius of the vertical curve should be larger than 36,000 m.

The former Science and Technology Division of the Ministry of Railways suggested, according to relevant norms [5], that to ensure riding comfort, the curve induced by uneven settlement must meet the following equation.

$$
\Delta S=\frac{\Delta L^{2}}{4 R_{a}}
$$

Here $\Delta S$ is the maximum non-uniform subsidence and $\Delta L$ is the length of the vertical curve.

Therefore, the maximum settlement of a $50-\mathrm{m}$ orbital base is set to $17 \mathrm{~mm}$ for a passenger-dedicated line with a train traveling at $300 \mathrm{~km}$ per hour. As the warning method mentioned in the previous section suggests, a warning of uneven subsidence should be issued when the absolute value of subsidence of its adjacent monitoring points in a certain period reaches $2.4 \mathrm{~mm}$. The warning threshold of continuous non-uniform settlement corresponds to $75 \%$ of the maximum value; i.e., $13 \mathrm{~mm}$.

\section{Conclusions}

This paper presented engineering surveying norms and experience of practical applications. The following conclusions were drawn regarding the warning of post-construction subsidence and deformation under high-speed railway tracks. 
(1) The core index of deformation warning, post-construction settlement, must be within $15 \mathrm{~mm}$.

(2) For isolated monitoring points of subsidence, warnings of slow settlement after construction should be issued for settlement exceeding $0.3 \mathrm{~mm}$ weekly or $1.2 \mathrm{~mm}$ monthly.

(3) When there is sudden subsidence at a monitoring point, the difference in the absolute value of settlement before and after should be less than $2 \mathrm{~mm}$.

(4) For passenger-dedicated lines with trains reaching a speed of $300 \mathrm{~km}$ per hour, the radius of the vertical curve ought to exceed $36,000 \mathrm{~m}$.

(5) The maximum settlement of a 50-m orbital base is $17 \mathrm{~mm}$ for a passenger-dedicated line with a train traveling at $300 \mathrm{~km}$ per hour. A warning of uneven subsidence should be issued when the absolute value of point's subsidence reaches $2.4 \mathrm{~mm}$. The threshold for a warning of continuous non-uniform settlement should be 13 $\mathrm{mm}$.

\section{Acknowledgements}

This research is supported by the Educational Commission of Hebei Province (No. Z2012109) at the Shijiazhuang Institute of Railway Technology in Shijiazhuang.

\section{References}

[1] Chen, S.X., Song, J. and Zhou, Q.N. (2010) Theory and Practice of Observation and Evaluation for High-Speed Railway Subsidence Deformation. China Railway Publishing House, Beijing.

[2] TB 10601-2009 (2009) Specification for Measurement of High-Speed Railway Engineering.

[3] Chinese Railway Construction Standards No.5 (2005) Guide for design of Ballastless Passenger Dedicated Railway Line.

[4] Chinese Railway Construction Standards No.147 (2008) Temporary Regulations on the Design of New Railway Line with 300 - $350 \mathrm{~km}$ per Hour.

[5] Chinese Railway Construction Standards (2005) Implementation Principles and Suggestions for Geotechnical Structures of New Slab Tracks. 